\title{
Automated Processing of Dynamic Contrast-Enhanced MRI: Correlation of Advanced Pharmacokinetic Metrics with Tumor Grade in Pediatric Brain Tumors
}

\author{
(D) S. Vajapeyam, (DC. Stamoulis, DK. Ricci, (D) M. Kieran, and DT. Young Poussaint
}

\begin{abstract}
BACKGROUND AND PURPOSE: Pharmacokinetic parameters from dynamic contrast-enhanced MR imaging have proved useful for differentiating brain tumor grades in adults. In this study, we retrospectively reviewed dynamic contrast-enhanced perfusion data from children with newly diagnosed brain tumors and analyzed the pharmacokinetic parameters correlating with tumor grade.
\end{abstract}

MATERIALS AND METHODS: Dynamic contrast-enhanced MR imaging data from 38 patients were analyzed by using commercially available software. Subjects were categorized into 2 groups based on pathologic analyses consisting of low-grade (World Health Organization I and II) and high-grade (World Health Organization III and IV) tumors. Pharmacokinetic parameters were compared between the 2 groups by using linear regression models. For parameters that were statistically distinct between the 2 groups, sensitivity and specificity were also estimated.

RESULTS: Eighteen tumors were classified as low-grade, and 20, as high-grade. Transfer constant from the blood plasma into the extracellular extravascular space ( $\left.K^{\text {trans }}\right)$, rate constant from extracellular extravascular space back into blood plasma $\left(K_{\text {ep }}\right)$, and extracellular extravascular volume fraction $\left(V_{e}\right)$ were all significantly correlated with tumor grade; high-grade tumors showed higher $K^{\text {trans }}$, higher $K_{\text {ep }}$, and lower $\mathrm{V}_{\mathrm{e}}$. Although all 3 parameters had high specificity (range, 82\%-100\%), $\mathrm{K}_{\mathrm{ep}}$ had the highest specificity for both grades. Optimal sensitivity was achieved for $\mathrm{V}_{\mathrm{e}}$, with a combined sensitivity of $76 \%$ (compared with $71 \%$ for $K^{\text {trans }}$ and $\mathrm{K}_{\text {ep }}$ ).

CONCLUSIONS: Pharmacokinetic parameters derived from dynamic contrast-enhanced MR imaging can effectively discriminate lowand high-grade pediatric brain tumors.

ABBREVIATIONS: IAUGC $_{60}=$ initial area under gadolinium curve at 60 seconds; $\mathrm{DCE}=$ dynamic contrast-enhanced; $\mathrm{K}_{\mathrm{ep}}=$ rate constant from extracellular extravascular space back into blood plasma; $K^{\text {trans }}=$ transfer constant from the blood plasma into the extracellular extravascular space; $V_{\mathrm{e}}=$ extracellular extravascular volume fraction; $V_{\mathrm{p}}=$ fractional blood plasma volume

$\mathbf{P}$ ediatric brain tumors are the most common cause of death from solid tumors, with an incidence rate of 5.57 cases per $100,000 .{ }^{1}$ Recent advances in the molecular characterization and treatment of brain tumors ${ }^{2}$ have made their proper classification by using imaging techniques critical. Conventional MR imaging is the technique of choice for preoperative diagnosis and evaluation of the child with an intracranial neoplasm because of its multipla-

Received May 11, 2016; accepted August 1.

From the Departments of Radiology (S.V., C.S., T.Y.P.) and Neurology (C.S.), Boston Children's Hospital, Boston, Massachusetts; Cancer Center (K.R.), Massachusetts General Hospital, Boston, Massachusetts; Department of Pediatric Oncology (M.K.), Dana-Farber Cancer Center, Boston, Massachusetts; and Harvard Medical School (S.V., C.S., M.K., T.Y.P.), Boston, Massachusetts.

Preliminary results previously presented at: Annual Meeting of the Radiological Society of North America, November 30 to December 5, 2014; Chicago, Illinois.

Please address correspondence to Sridhar Vajapeyam, PhD, Department of Radiology, Boston Children's Hospital, 300 Longwood Ave, Boston, MA 02115; e-mail:

sridhar.vajapeyam@childrens.harvard.edu

http://dx.doi.org/10.3174/ajnr.A4949 nar capability and superior anatomic detail and resolution. Advanced imaging techniques such as MR perfusion are used to complement structural imaging, providing further insight into tumor physiology. In adults, dynamic contrast-enhanced (DCE) MR perfusion has been used to determine tumor grade ${ }^{3-5}$ and to distinguish pseudoprogression from tumor recurrence, ${ }^{6}$ thus affecting treatment.

While dynamic susceptibility contrast perfusion and DCE-MR perfusion in adult brain tumors have been extensively studied in the literature, particularly for monitoring tumor antiangiogenesis treatments, ${ }^{7-11}$ DCE-MR imaging studies in pediatric brain tumors have been scarce $e^{12-18}$ and have not focused on tumor grading.

Multiparametric methods to characterize and monitor brain tumors have also shown great promise. ${ }^{19,20}$ DCE-MR imaging is particularly suited to multiparametric analyses that require image registration between modalities because it does not have geometric distortion due to susceptibility effects, unlike other advanced 
MR imaging modalities such as dynamic susceptibility contrast perfusion imaging and diffusion imaging.

In this study, we retrospectively reviewed DCE perfusion data from children with newly diagnosed brain tumors during a 2-year period at our institution and analyzed the pharmacokinetic tumor permeability perfusion parameters correlating with tumor grade.

\section{MATERIALS AND METHODS \\ Subjects}

The study was performed with the approval of the institutional review board at the Dana Farber Cancer Institute. Children who presented with a brain mass and had undergone DCE perfusion studies were included. Of 52 patients identified with brain masses who had undergone DCE imaging, 6 patients had final diagnoses that were not brain tumors, 6 had nonenhancing tumors and therefore were not eligible for DCE-MR imaging analysis, and 2 patients were excluded due to motion. Thirty-eight patients were included in this study: 14 girls and 24 boys; age range, $0.30-18.14$ years (median age, 6.01 years; mean age, 7.83 years).

\section{MR Imaging Acquisition}

All MR imaging studies were performed on a 3T scanner (Siemens, Erlangen, Germany). Standard MR imaging in all patients consisted of sagittal T1, axial T2-weighted, axial T2 FLAIR, axial diffusion-weighted, and multiplanar precontrast and postcontrast T1 images. All patients underwent a dynamic contrast-enhanced MR imaging protocol as follows:

1) Variable flip angle echo-spoiled gradient echo T1-mapping sequences by using flip angles of $15^{\circ}, 10^{\circ}, 5^{\circ}$, and $2^{\circ}$; TR $=5$ seconds; $\mathrm{TE}=$ minimum; FOV $=240 \mathrm{~mm}$; section thickness $=5 \mathrm{~mm}$.

2) DCE-MR imaging sequence consisting of 50 phases, 7 seconds apart, with flip angle $=15^{\circ}, \mathrm{TR}=4$ seconds, $\mathrm{TE}=$ minimum. FOV, section thickness, and scan locations were identical to those in the T1 mapping sequences. A single bolus of gadobutrol (Gadavist, $0.1 \mathrm{mmol} / \mathrm{kg}$ body weight; Bayer Schering Pharma, Berlin, Germany) was injected 20 seconds after the start of scanning at an injection rate of $2 \mathrm{~mL} / \mathrm{s}$.

\section{MR Imaging Postprocessing}

MR images were transferred to a VersaVue workstation (iCAD, Nashua, New Hampshire) for automated processing by using OmniLook software (iCad). T1 maps were automatically calculated from the variable flip angle images ${ }^{21}$ to yield native $\mathrm{T} 1$ of the tissue. The 2-compartment Tofts model ${ }^{22}$ was used for the voxelwise calculation of advanced pharmacokinetic parameters such as the transfer constant from the blood plasma into the extracellular extravascular space $\left(K^{\text {trans }}\right)$, rate constant from extracellular extravascular space back into blood plasma $\left(\mathrm{K}_{\mathrm{ep}}\right)$, extracellular extravascular volume fraction $\left(\mathrm{V}_{\mathrm{e}}\right)$, fractional blood plasma volume $\left(\mathrm{V}_{\mathrm{p}}\right)$, and initial area under gadolinium curve at 60 seconds $\left(\right.$ IAUGC $_{60}$ ). The model of Weinmann et $\mathrm{al}^{23}$ for blood plasma concentration was used along with a relaxivity of $5.1 \mathrm{~L} \cdot \mathrm{mmol}^{-1} \cdot \mathrm{s}^{-1}$ for the contrast agent.

ROIs were drawn on each section of tumor around contrastenhancing portions of the tumor by an imaging data analyst or by a PhD scientist and verified by a Certificate of Added Qualification-certified neuroradiologist, and the mean (over voxels) and
SDs of each of the variables were recorded for statistical analysis. We included only voxels that could be fit to the model in the computation of mean and SD, excluding areas of cyst, and we took care to exclude vessels from the ROI.

\section{Statistical Analysis}

Subjects were categorized into 2 groups based on pathologic analyses consisting of low-grade (World Health Organization I and II) and high-grade (World Health Organization III and IV) tumors. All the pharmacokinetic parameters described above, along with T1 of the tissue, were compared between the 2 groups by using linear regression models with each parameter as a dependent variable (the outcome) and tumor grade as a categoric independent variable (low-grade $=0$, high-grade $=1$ ). For parameters significantly distinct between the 2 groups, sensitivity and specificity were also estimated.

Given the non-normal distribution of all parameters, summary statistics reported throughout included median and interquartile ranges. In addition, confidence intervals were estimated via bootstrapping with replacement (2000 draws).

Sensitivity and specificity were estimated as follows: First, the CIs for individual parameter medians were used for thresholding. For each parameter, there were 2 confidence intervals, 1 for the median of high-grade tumors and 1 for the median of low-grade tumors. The lower CI for intervals of statistically higher values and the upper CI for intervals of statistically lower values were used as thresholds. For example, if a parameter median was significantly higher for high-grade than low-grade tumors, then any high-grade parameter value at or above the lower CI for the group median was considered a true-positive and any value below this CI was considered a false-negative (or a false-positive for lowgrade). Similarly, any low-grade parameter value at or below the upper CI for the group median was considered a true-positive, and any value above this CI was considered a false-negative (or a false-positive for high-grade).

\section{RESULTS}

Of the 38 patients who had enhancing tumors confirmed by biopsy, 18 tumors were classified as low-grade (7 pilocytic astrocytomas, 3 low-grade gliomas with piloid features, 3 low-grade gliomas, 1 low-grade ependymoma, 1 atypical meningioma World Health Organization grade II, 1 hemangioblastoma grade I, 1 ganglioglioma grade I-II, 1 low-grade histiocytic sarcoma) and 20 were classified as high-grade (11 medulloblastomas, 3 glioblastoma multiformes, 2 anaplastic ependymomas, 1 high-grade sarcoma, 1 choroid plexus carcinoma, 1 germinomatous germ cell tumor, and 1 high-grade glioma).

There was no statistically significant difference $(P=.8)$ between patient age and tumor grade. For low-grade tumors, the median patient age was 5.52 years ( 25 th to 75 th quartiles $=2.62-$ 12.97 years), and for high-grade tumors, the median patient age was 6.88 years ( 25 th to 75 th quartiles $=3.72-19.38$ years).

The linear regression model results of the pharmacokinetic parameters are summarized in Table 1 . The regression coefficient corresponding to tumor grade, its confidence intervals, standard error, significance ( $P$ value), and Wald statistics are included for parameters that were found to be significantly correlated with 


\begin{tabular}{|c|c|c|c|c|c|}
\hline Parameter & $\begin{array}{l}\text { Regression } \\
\text { Coefficient }\end{array}$ & $95 \% \mathrm{Cl}$ & $\begin{array}{l}\text { Standard } \\
\text { Error }\end{array}$ & $\begin{array}{c}P \\
\text { Value }\end{array}$ & $\begin{array}{l}\text { Wald } \\
\text { Statistic }\end{array}$ \\
\hline$K^{\text {trans }}$ & 1.54 & $(0.69-2.39)$ & 0.42 & $<.001$ & 13.42 \\
\hline$K_{\mathrm{ep}}$ & 10.22 & $(6.12-14.33)$ & 2.02 & $<.001$ & 25.54 \\
\hline & -0.11 & $(-0.15$ to -0.06$)$ & 0.02 & $<.001$ & 21.85 \\
\hline${ }^{\prime A U G C} C_{60}$ & & & & .12 & \\
\hline$V_{p}$ & & & & .4 & \\
\hline $\mathrm{T}_{10}$ & & & & .34 & \\
\hline
\end{tabular}

Note:- $\mathrm{T}_{10}$ indicates $\mathrm{Tl}$ of tissue.

Table 2: Summary statistics, sensitivity, and specificity of permeability parameters statistically correlated with tumor grade

\begin{tabular}{llllc}
\hline Parameter & Median & $\begin{array}{c}95 \% \text { Cl for } \\
\text { Median }\end{array}$ & Sensitivity & Specificity \\
\hline$K^{\text {trans }}$ & L: 0.09 & $(0.06-0.13)$ & $70 \%-72 \%$ & $90 \%-100 \%$ \\
& H: 0.89 & $(0.57-1.85)$ & & \\
$\mathrm{K}_{\mathrm{ep}}$ & $\mathrm{L}: 0.66$ & $(0.33-0.97)$ & $70 \%-72 \%$ & $100 \%$ \\
$\mathrm{~V}_{\mathrm{e}}$ & $\mathrm{H}: 6.76$ & $(4.99-13.95)$ & & \\
& L: 0.23 & $(0.19-0.26)$ & $75 \%-78 \%$ & $82 \%-100 \%$ \\
\hline
\end{tabular}

Note:- L indicates low-grade; $\mathrm{H}$, high-grade.

tumor grade. These included $K^{\text {trans }}, \mathrm{K}_{\mathrm{ep}}$, and $\mathrm{V}_{\mathrm{e}}$. Specifically, $K^{\text {trans }}$ was statistically higher for high-grade tumors (median $=$ $0.89,25$ th to 75 th quartiles $=0.46-2.67$ ) than for low-grade tumors $($ median $=0.09,25$ th to 75 th quartiles $=0.04-0.13) . \mathrm{K}_{\mathrm{ep}}$ was statistically higher for high-grade tumors (median $=6.76$, 25th to 75th quartiles $=3.77-16.88)$ than for low-grade tumors (median $=0.66,25$ th to 75 th quartiles $=0.29-1.04) . \mathrm{V}_{\mathrm{e}}$ was statistically lower for high-grade tumors (median $=0.12,25$ th to 75th quartiles $=0.11-0.15$ ) than for low-grade tumors (median $=0.23,25$ th to 75 th quartiles $=0.19-0.26$ ). Information on the range, sensitivity, and specificity of these parameters is provided in Table 2.

\section{$\mathbf{K}^{\text {trans }}$}

For low-grade tumors, $K^{\text {trans }}$ was in the range of 0.02-0.52 (median $=0.09 ; 95 \%$ CI for the median $=0.06-0.13)$. For high-grade tumors, it was in the range of 0.09-6.19 (median $=0.89 ; 95 \%$ $\mathrm{CI}=0.57-1.85)$. Based on the CI thresholds, there were 14 highgrade and 13 low-grade true-positives, resulting in a 71\% (27/38) combined sensitivity of this parameter to detect high- or lowgrade tumors. Individually, the sensitivity of this parameter to detect high-grade tumors was 70\% (14/20), and for low-grade tumors, it was $72 \%(13 / 18)$. In addition, there were 2 high-grade tumors with values below the threshold for low-grade. These were considered false-positives for low-grade. There were no low-grade tumors with values above the threshold for high-grade. Consequently, the specificity of this parameter was 100\% (18/18) for highgrade tumors and $90 \%$ (18/20) for low-grade tumors.

\section{$\boldsymbol{K}_{\text {ep }}$}

For low-grade tumors, $\mathrm{K}_{\mathrm{ep}}$ was in the range of 0.1-3.13 (median $=0.66 ; 95 \% \mathrm{CI}=0.33-0.97)$. For high-grade tumors, $\mathrm{K}_{\mathrm{ep}}$ was in the range of 1.01-29.67 (median $=6.76 ; 95 \% \mathrm{CI}=4.99-13.95$ ). Based on the CI thresholds, there were 14 high-grade and 13 lowgrade true-positives, resulting in a combined sensitivity of $71 \%$ (27/
38). Individually, the sensitivity of this parameter to detect highgrade tumors was $70 \%(14 / 20)$ and $72 \%$ (13/18) for low-grade tumors. There were no false-positives in either group; thus, specificity was $100 \%$ (18/18) for high-grade tumors and 100\% (20/20) for low-grade tumors.

$V_{e}$

For low-grade tumors, $\mathrm{V}_{\mathrm{e}}$ was in the range of 0.11-0.48 (median $=0.23 ; 95 \% \mathrm{CI}=0.19-0.26)$. For high-grade tumors, it was in the range of $0.04-0.18$ (median $=0.12 ; 95 \% \mathrm{CI}=0.11-0.15)$. Based on the CI thresholds, there were 15 high-grade and 14 lowgrade true-positives, resulting in a combined sensitivity of $76 \%$ (29/38). Individually, the sensitivity of this parameter to detect high-grade tumors was 75\% (15/20) and 78\% (14/18) for lowgrade tumors. There were 4 low-grade tumors with values below the threshold for high-grade. These were considered false-positives for high-grade. There were no false-positives for low-grade. Consequently, the specificity of this parameter for high-grade was $82 \%(18 / 22)$ and $100 \%$ (20/20) for low-grade.

\section{DISCUSSION}

Pediatric brain tumors encountered in a clinical setting differ significantly in tumor type from those seen in adults; therefore, predicting tumor grade by using MR imaging in a pediatric clinical setting presents a unique set of issues. While vessel permeability metrics derived from DCE-MR imaging have been associated with tumor grade in adult populations, ${ }^{24-26}$ such studies in pediatric brain tumors have been lacking.

Dynamic susceptibility contrast perfusion MR imaging has been studied in children by Ho et $\mathrm{al}^{27}$ to associate tumor grade with maximal relative cerebral blood volume and with the postbolus shape of the enhancement curve. ${ }^{28}$ Koob et al ${ }^{19}$ used a multiparametric approach to show that the highest grading accuracy was achieved by using a combination of parameters derived from diffusion and DSC perfusion imaging. Yeom et $\mathrm{al}^{29}$ used arterial spin-labeling to measure perfusion and found that maximal relative tumor blood flow of high-grade tumors was significantly higher than that of low-grade tumors.

Our results suggest that the transfer constants, both $K^{\text {trans }}$ and $\mathrm{K}_{\mathrm{ep}}$, are significantly distinct between the low-grade and highgrade groups. Several studies have examined the role of $K^{\text {trans }}$ and have shown $K^{\text {trans }}$ correlates well with tumor grade, particularly in gliomas in adults. ${ }^{24-26,30-32}$ The role of angiogenesis in promoting leakiness of the tumor vasculature and development of new vessels is well-documented, and our findings of increased $K^{\text {trans }}$ in higher grade tumors supports that hypothesis. $K^{\text {trans }}$ in gliomas has also been shown to be a marker of progression ${ }^{31,33}$ in adults.

Our study shows that pediatric low-grade tumors in fact have a higher $\mathrm{V}_{\mathrm{e}}$ compared with high-grade tumors, contrary to findings in adult tumors showing lower $\mathrm{V}_{\mathrm{e}}$ in low-grade adult tumors. ${ }^{24-26}$ In fact, the optimal sensitivity appears to be achieved for $\mathrm{V}_{\mathrm{e}}$, with a combined sensitivity of $76 \%$ (compared with $71 \%$ for $K^{\text {trans }}$ and $\mathrm{K}_{\mathrm{ep}}$ ) and individual sensitivities of $75 \%$ and $78 \%$, respectively, for high- and low-grade tumors. The role of $\mathrm{V}_{\mathrm{e}}$, which is an indicator of extracellular extravascular space, is poorly understood in the brain tumor literature. Our findings concur with the theory that the higher cellularity in high-grade tumors would lead 


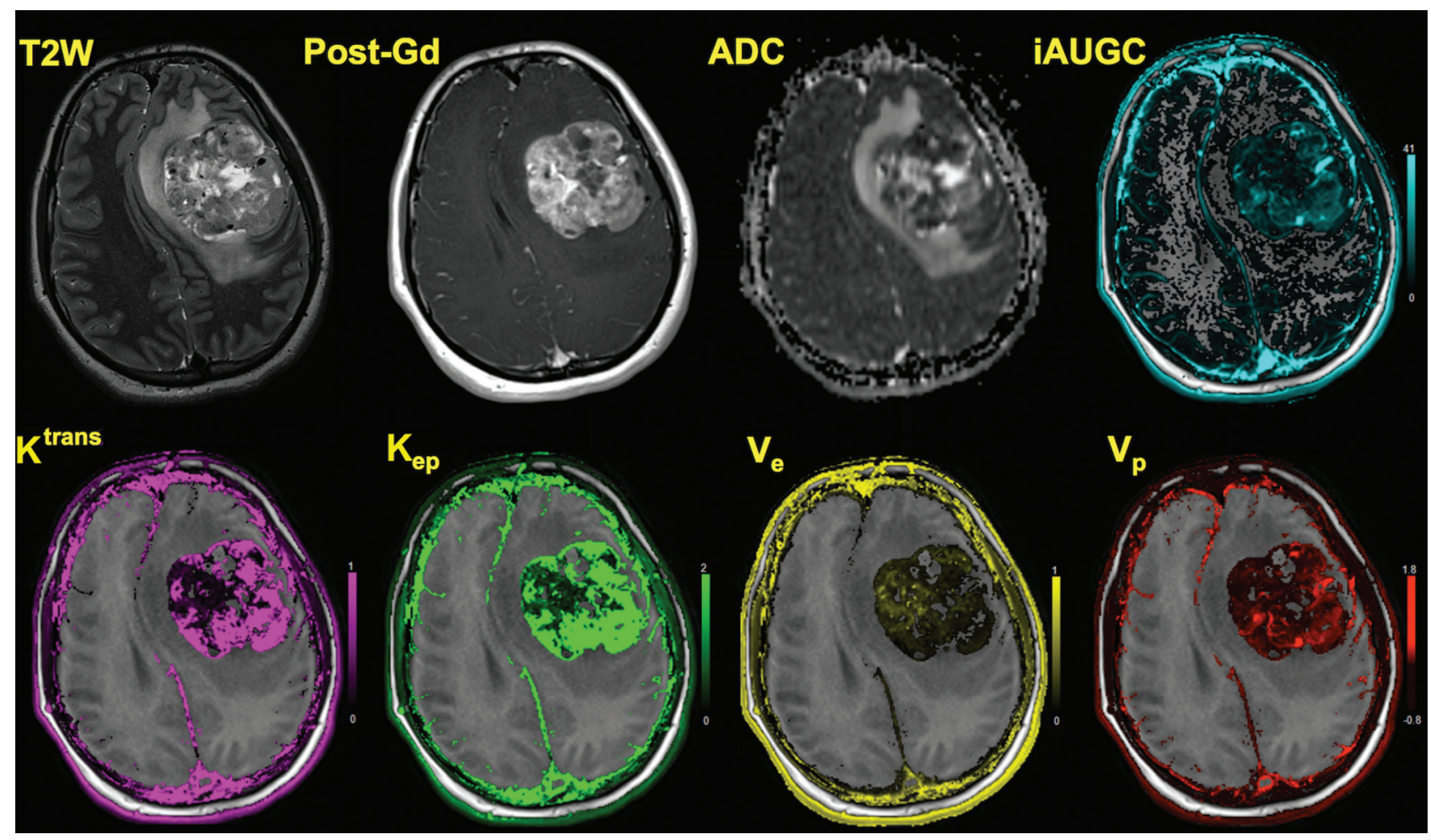

FIG 1. A 17-year-old girl with an anaplastic grade III ependymoma is shown. In addition to axial T2-weighted and axial postcontrast T1-weighted images, corresponding maps shown are ADC, IAUGC ${ }_{60}, K^{\text {trans }}, K_{e p}, V_{e}$, and $V_{p}$. Axial T2 image demonstrates heterogeneous tumor in the left frontal lobe with regions of hypointensity. Axial T1 postcontrast image demonstrates heterogeneous enhancement. ADC image demonstrates regions of restricted diffusion within the tumor. High $K^{\text {trans }}$ and $K_{\text {ep }}$ are readily apparent in the overlaid color maps, and $\mathrm{V}_{\mathrm{e}}$ is low.

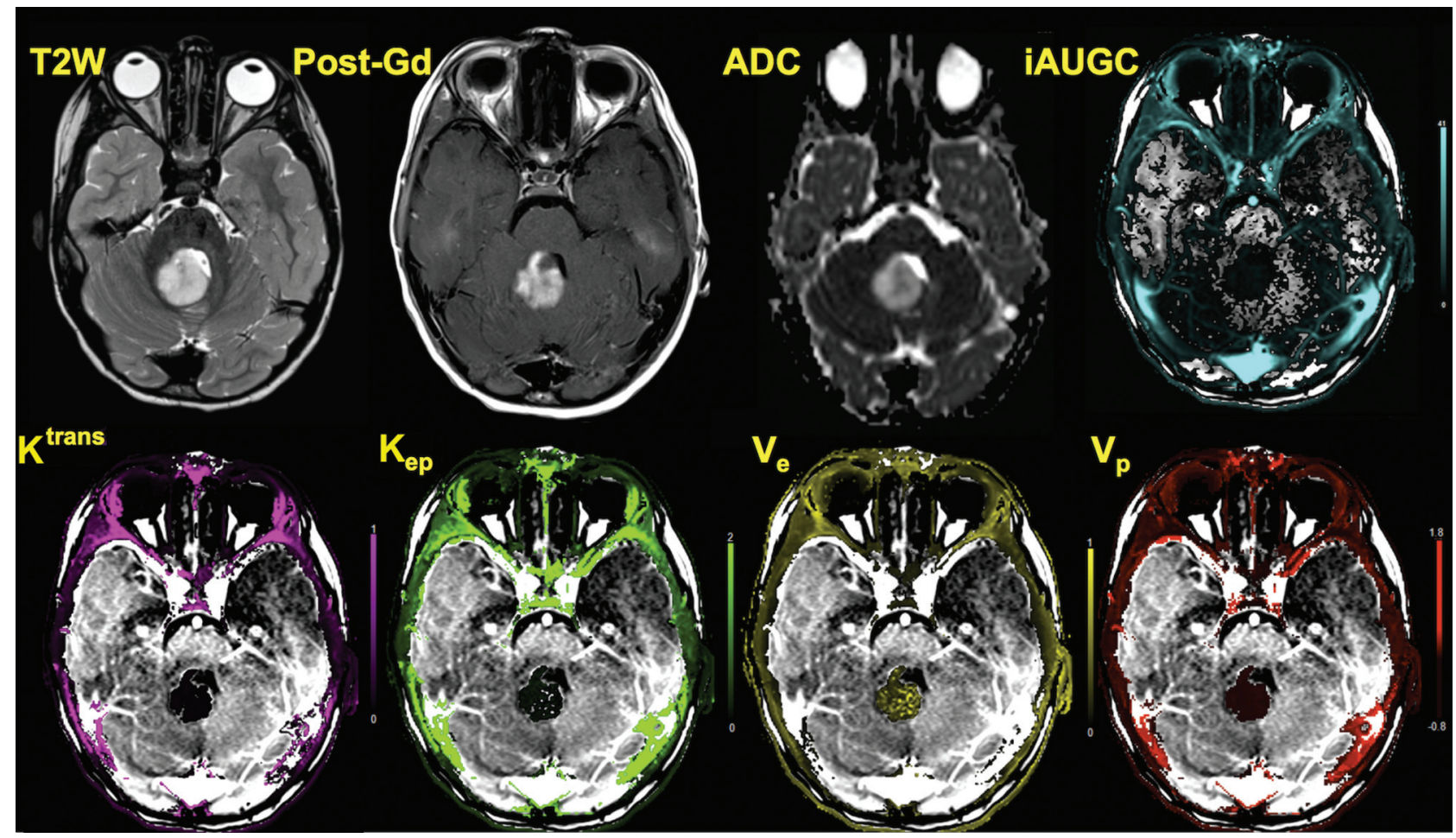

FIG 2. A 3-year-old boy with posterior fossa pilocytic astrocytoma is shown. Axial T2 image shows a T2 hyperintense mass in the vermis, which shows enhancement and increased diffusion. Permeability images show that though there is marked enhancement typical of these tumors, $K^{\text {trans }}$ and $\mathrm{K}_{\mathrm{ep}}$ are considerably lower, whereas $\mathrm{V}_{\mathrm{e}}$ is higher throughout the tumor compared with the high-grade tumor shown in Fig 1. 
to a decreased extracellular space due to the closely packed tumor cells, and hence lower $\mathrm{V}_{\mathrm{e}}$. As seen in Figs 1 and 2, the areas of decreased $\mathrm{V}_{\mathrm{e}}$ also correlate with areas of decreased ADC, further confirming our hypothesis. Mills et $\mathrm{al}^{34}$ however failed to find the expected correlation in a voxelwise analysis between $\mathrm{V}_{\mathrm{e}}$ and $\mathrm{ADC}$ in adult glioblastoma multiformes, possibly due to the confounding effects of the heterogeneous nature of those tumors.

All 3 parameters had high specificity, in the range $82 \%-100 \%$. For low-grade tumors, their specificity was $90 \%-100 \%$, and for high-grade tumors, the specificity was $82 \%-100 \%$. $\mathrm{K}_{\text {ep }}$ had the highest specificity (100\%) for both grades.

One of the limitations of this study is that DCE-MR imagingderived pharmacokinetic parameters are heavily dependent on the model and input parameters used ${ }^{12,22}$ and are thought to be difficult to standardize. Some of these parameters may not be as critical as previously thought. For example, Larsson et $\mathrm{al}^{35}$ recently found that there was no significant difference between using $\mathrm{T} 1$ derived from a mapping sequence and using a fixed T1 in high-grade gliomas in adults. Because all our subjects were analyzed by using identical model parameters, this finding may not be that critical in this study. Last, the heterogeneity of tumor types and the relatively small sample in this study are also a limitation. Previous studies, however, have investigated smaller samples, so our findings are based on a comparatively larger sample. Nevertheless, this work may be validated in a larger cohort of children with pediatric brain tumors in future studies.

\section{CONCLUSIONS}

Dynamic contrast-enhanced perfusion MR imaging is useful in a clinical setting for the differential diagnosis and grading of pediatric brain tumors. Pharmacokinetic parameters such as $\mathrm{V}_{\mathrm{e}}$, $K^{\text {trans }}$, and $K_{\text {ep }}$ can be used to differentiate low- and high-grade tumors to facilitate treatment planning and determine prognosis and have comparable specificities for tumor grade. In our study, the parameter $\mathrm{K}_{\mathrm{ep}}$ had the highest specificity for both grades. Of the pharmacokinetic parameters studied, $\mathrm{V}_{\mathrm{e}}$ offers the highest sensitivity (overall 76\%) for determining tumor grade.

\section{REFERENCES}

1. Ostrom QT, Gittleman H, Fulop J, et al. CBTRUS statistical report: primary brain and central nervous system tumors diagnosed in the United States in 2008-2012. Neuro Oncol 2015;17(suppl 4):iv1-iv62 CrossRef Medline

2. Pollack IF. Multidisciplinary management of childhood brain tumors: a review of outcomes, recent advances, and challenges. J Neurosurg Pediatr 2011;8:135-48 CrossRef Medline

3. Arevalo-Perez J, Kebede AA, Peck KK, et al. Dynamic contrast-enhanced MRI in low-grade versus anaplastic oligodendrogliomas. J Neuroimaging 2016;26:366-71 CrossRef Medline

4. Zhao J, Yang ZY, Luo BN, et al. Quantitative evaluation of diffusion and dynamic contrast-enhanced MR in tumor parenchyma and peritumoral area for distinction of brain tumors. PLoS One 2015;10: e0138573 CrossRef Medline

5. Zhang N, Zhang L, Qiu B, et al. Correlation of volume transfer coefficient Ktrans with histopathologic grades of gliomas. J Magn Reson Imaging 2012;36:355-63 CrossRef Medline

6. Thomas AA, Arevalo-Perez J, Kaley T, et al. Dynamic contrast enhanced T1 MRI perfusion differentiates pseudoprogression from recurrent glioblastoma. J Neurooncol 2015;125:183-90 CrossRef Medline

7. Schmainda KM, Prah M, Connelly J, et al. Dynamic-susceptibility contrast agent MRI measures of relative cerebral blood volume predict response to bevacizumab in recurrent high-grade glioma. Neuro Oncol 2014;16:880-88 CrossRef Medline

8. Harris RJ, Cloughesy TF, Hardy AJ, et al. MRI perfusion measurements calculated using advanced deconvolution techniques predict survival in recurrent glioblastoma treated with bevacizumab. J Neurooncol 2015;122:497-505 CrossRef Medline

9. Arevalo-Perez J, Thomas AA, Kaley T, et al. T1-weighted dynamic contrast-enhanced MRI as a noninvasive biomarker of epidermal growth factor receptor vIII status. AJNR Am J Neuroradiol 2015;36: 2256-61 CrossRef Medline

10. Jain R, Poisson LM, Gutman D, et al. Outcome prediction in patients with glioblastoma by using imaging, clinical, and genomic biomarkers: focus on the nonenhancing component of the tumor. Radiology 2014;272:484-93 CrossRef Medline

11. Pope WB. Predictive imaging marker of bevacizumab efficacy: perfusion MRI. Neuro Oncol 2015;17:1046-47 CrossRef Medline

12. Lam S, Lin Y, Warnke PC. Permeability imaging in pediatric brain tumors. Transl Pediatr 2014;3:218-28 CrossRef Medline

13. Gururangan S, Fangusaro J, Poussaint TY, et al. Efficacy of bevacizumab plus irinotecan in children with recurrent low-grade gliomas: a Pediatric Brain Tumor Consortium study. Neuro Oncol 2014;16:310-17 CrossRef Medline

14. Zukotynski KA, Fahey FH, Vajapeyam S, et al. Exploratory evaluation of MR permeability with 18F-FDG PET mapping in pediatric brain tumors: a report from the Pediatric Brain Tumor Consortium. J Nucl Med 2013;54:1237-43 CrossRef Medline

15. Thompson EM, Guillaume DJ, Dosa E, et al. Dual contrast perfusion MRI in a single imaging session for assessment of pediatric brain tumors. J Neurooncol 2012;109:105-14 CrossRef Medline

16. Gururangan S, Fangusaro J, Young Poussaint T, et al. Lack of efficacy of bevacizumab + irinotecan in cases of pediatric recurrent ependymoma: a Pediatric Brain Tumor Consortium study. Neuro Oncol 2012;14:1404-12 CrossRef Medline

17. Gururangan S, Chi SN, Young Poussaint T, et al. Lack of efficacy of bevacizumab plus irinotecan in children with recurrent malignant glioma and diffuse brainstem glioma: a Pediatric Brain Tumor Consortium study. J Clin Oncol 2010;28:3069-75 CrossRef Medline

18. Liu HL, Chang TT, Yan FX, et al. Assessment of vessel permeability by combining dynamic contrast-enhanced and arterial spin labeling MRI. NMR Biomed 2015;28:642-49 CrossRef Medline

19. Koob M, Girard N, Ghattas B, et al. The diagnostic accuracy of multiparametric MRI to determine pediatric brain tumor grades and types. J Neurooncol 2016;127:345-53 CrossRef Medline

20. Law M, Yang S, Wang H, et al. Glioma grading: sensitivity, specificity, and predictive values of perfusion MR imaging and proton MR spectroscopic imaging compared with conventional MR imaging. AJNR Am J Neuroradiol 2003;24:1989-98 Medline

21. Fram EK, Herfkens RJ, Johnson GA, et al. Rapid calculation of T1 using variable flip angle gradient refocused imaging. Magn Reson Imaging 1987;5:201-08 CrossRef Medline

22. Tofts PS. Modeling tracer kinetics in dynamic Gd-DTPA MR imaging. J Magn Reson Imaging 1997;7:91-101 CrossRef Medline

23. Weinmann HJ, Laniado M, Mützel W. Pharmacokinetics of GdDTPA/dimeglumine after intravenous injection into healthy volunteers. Physiol Chem Phys Med NMR 1984;16:167-72 Medline

24. Abe T, Mizobuchi Y, Nakajima K, et al. Diagnosis of brain tumors using dynamic contrast-enhanced perfusion imaging with a short acquisition time. Springerplus 2015;4:88 CrossRef Medline

25. Li X, Zhu Y, Kang H, et al. Glioma grading by microvascular permeability parameters derived from dynamic contrast-enhanced MRI and intratumoral susceptibility signal on susceptibility weighted imaging. Cancer Imaging 2015;15:4 CrossRef Medline

26. Choi HS, Kim AH, Ahn SS, et al. Glioma grading capability: comparisons among parameters from dynamic contrast-enhanced MRI and ADC value on DWI. Korean J Radiol 2013;14:487-92 CrossRef Medline

27. Ho CY, Cardinal JS, Kamer AP, et al. Relative cerebral blood volume 
from dynamic susceptibility contrast perfusion in the grading of pediatric primary brain tumors. Neuroradiology 2015;57:299-306 CrossRef Medline

28. Ho CY, Cardinal JS, Kamer AP, et al. Contrast leakage patterns from dynamic susceptibility contrast perfusion MRI in the grading of primary pediatric brain tumors. AJNR Am J Neuroradiol 2016;37: 544-51 CrossRef Medline

29. Yeom KW, Mitchell LA, Lober RM, et al. Arterial spin-labeled perfusion of pediatric brain tumors. AJNR Am J Neuroradiol 2014;35: 395-401 CrossRef Medline

30. Roberts HC, Roberts TPL, Ley S, et al. Quantitative estimation of microvascular permeability in human brain tumors: correlation of dynamic Gd-DTPA-enhanced MR imaging with histopathologic grading. Acad Radiol 2002;9:S151-55 CrossRef Medline

31. Mills SJ, Patankar TA, Haroon HA, et al. Do cerebral blood volume and contrast transfer coefficient predict prognosis in human glioma? AJNR Am J Neuroradiol 2006;27:853-58 Medline
32. Patankar TF, Haroon HA, Mills SJ, et al. Is volume transfer coefficient (K(trans)) related to histologic grade in human gliomas? AJNR Am J Neuroradiol 2005;26:2455-65 Medline

33. Cao Y, Nagesh V, Hamstra D, et al. The extent and severity of vascular leakage as evidence of tumor aggressiveness in high-grade gliomas. Cancer Res 2006;66:8912-17 CrossRef Medline

34. Mills SJ, Soh C, Rose CJ, et al. Candidate biomarkers of extravascular extracellular space: a direct comparison of apparent diffusion coefficient and dynamic contrast-enhanced MR imaging-derived measurement of the volume of the extravascular extracellular space in glioblastoma multiforme. AJNR Am J Neuroradiol 2010;31: 549-53 CrossRef Medline

35. Larsson C, Kleppesto M, Grothe I, et al. T1 in high-grade glioma and the influence of different measurement strategies on parameter estimations in DCE-MRI. J Magn Reson Imaging 2015;42:97-104 CrossRef Medline 